\title{
EKSISTENSI LGBT DI INDONESIA DALAM KAJIAN PERSPEKTIF HAM, AGAMA, DAN PANCASILA
}

\author{
Toba Sastrawan Manik ${ }^{1 *}$, Dwi Riyanti², Mukhamad Murdiono ${ }^{3}$, \\ Danang Prasetyo ${ }^{4}$ \\ ${ }^{13)}$ Universitas Negeri Yogyakarta, Yogyakarta, Indonesia \\ 2) Universitas Terbuka, Jakarta, Indonesia \\ 4) Sekolah Tinggi Pariwisata Ambarrukmo, Yogyakarta, Indonesia \\ *tobasastrawanmanik@gmail.com
}

\begin{abstract}
Gay, Bisexual, and Transgender (LGBT) in Indonesia from the perspective of human rights, Islam, and Pancasila. Research is qualitative using the method of literature study (library research). LGBT based on a religious point of view, especially Islam and Pancasila are declared forbidden and contrary culture. But, the state is in ambiguity in determining policy. The State of Indonesia faces a dilemma between Pancasila and Islam with the consistency and spirit of human rights enforcement in Indonesia since the Reformation Era. This manifestation of ambiguity appears to be the lack of clear regulation of LGBT. This gives rise to discriminatory attitudes towards LGBT people both psychologically, physically socially, culturally, and economically. This study recommends that the state should take a bold stance in determining the point of view of LGBT. LGBT citizens should still be treated equally. The absence of regulation against $L G B T$ is a manifestation of discrimination by the state. The state should give its perspective on LGBT in Indonesia.
\end{abstract}

Keywords: LGBT, Pancasila, Islam, Citizenship.

\begin{abstract}
Abstrak
Tujuan dari artikel ini ialah untuk mengkaji tentang eksistensi Lesbian, Gay, Biseksual, dan Transgender (LGBT) di Indonesia dari perspektif hak asasi manusia, Islam, dan Pancasila. Penelitian bersifat kualitatif dengan menggunakan metode kajian literatur (ibrary research). LGBT jika dipandang dari sudut agama khususnya Islam dan Pancasila jelas dinyatakan terlarang dan bertentangan dengan budaya Indonesia. Tapi, negara dalam keambiguan dalam menentukan kebijakan. Negara Indonesia menghadapi dilema antara Pancasila dan Islam dengan konsistensi dan semangat penegakan HAM di Indonesia sejak Era Reformasi. Manifestasi keambiguan ini tampak pada ketiadaan regulasi yang jelas terhadap LGBT. Hal ini menimbulkan sikap diskrimnasi terhadap kalangan LGBT baik secara psikis, fisik secara sosial, budaya, dan ekonomi. Rekomendasi dari kajian ini ialah negara harus berani mengambil sikap dalam menentukan sudut pandang terhadap LGBT. LGBT sebagai warga negara harus tetap diperlakukan sama. Ketiadaan regulasi terhadap kalangan LGBT merupakan manifestasi diskriminasi oleh negara. Negara harus memberikan sudut pandangnya sendiri terhadap LGBT di Indonesia.
\end{abstract}

Kata kunci: LGBT, Pancasila, Islam, Kewarganegaraan.

Sejarah Artikel: Diterima 2 Maret 2021 | Direvisi hingga 6 Agustus 2021

Diterima 11 Agustus 2021 | Publikasikan 27 September 2021

Copyright @ 2021, Toba Sastrawan Manik, Dwi Riyanti, Mukhamad Murdiono, 


\section{PENDAHULUAN}

Lesbian, Gay, Biseksual, dan Transgender atau disingkat dengan LGBT kembali menjadi diskusi publik akhir-akhir ini. Kelompok yang dianggap memiliki kelainan seksual ini direspon secara negatif oleh masyarakat umum karena dianggap amoral dan bertentangan dengan nilai-nilai moral, agama, dan Pancasila (Wibowo, 2015). Penolakan dari berbagai kalangan bahkan keinginan agar kelompok tersebut dikriminalisasi melalui UU sangat keras disuarakan khususnya kalangan pemuka agama.

Pro-Kontra terhadap kalangan ini tidak bisa dihindarkan. Kalangan Pro mengatakan LGBT merupakan ekspresi yang harus dihargai dan dilindungi oleh negara. LGBT dianggap merupakan bagian dari HAM. Kalangan Kontra mengatakan bahwa LGBT merupakan seks yang menyimpang dan bisa merusak tatanan sosial. Pendapat ini biasanya disuarakan oleh kalangan agama maupun budaya di Indonesia. Hal ini diperkuat oleh Santoso (2016) yang menyatakan masalah LGBT yang ada di Indonesia sudah menimbukan pro dan kontra. Mereka yang pro dengan LGBT menyatakan negara harus harus dapat mengkampanyekan sikap non diskriminatif antara lelaki, perempuan, trangender, heteroseksual, maupun homoseksual. Dilihat dari perspektif HAM, Pendukung dari LGBT menyatakan orientasi seksual merupakan manifestasi HAM. Bagi yang kontra terhadap LGBT menyatakan LGBT sebagai bentuk penyimpangan dari seksual yang tidak termasuk ke dalam kosep dasar HAM.

Dua pihak yang berbeda tersebut memiliki dasar logika dan argumentasi yang sangat berbeda sehingga mustahil mencapai titik temu. Dalam hal inilah negara perlu berperan adil, holistik, dan komprehensif sehingga memberikan pencerahan dan pegangan konkret. Afirmasinya hanya dengan kehadiran negara permasalahan tersebut bisa diselesaikan secara konstitusional. Terlepas dari pro-kontra tersebut, saat ini terdapat peningkatan kelompok tersebut di Indonesia. khususnya gay di daerah perkotaan seperti Bali, Jakarta, Suraabaya, dan Yogyakarta (Offord \& Cantrell, 2000). Bahkan kalangan ini juga sudah memiliki organisasi yakni Gaya Nusantara. Hebatnya lagi, organisasi ini merupakan organisasi Gay terbesar yang ada di Asia Tenggara dengan sebaran di 11 kota di Indonesia (Offord \& Cantrell, 2000). Hal yang sama diperoleh United Nation Development Program (UNDP) 2014 disebut yang menyebutkan bahwa 2013, ada dua jaringan nasional organisasi LGBT, dan 119 organisasi di 28 dari 34 provinsi di negara ini (UNDP, 2014). Hal ini menunjukkan bahwa dua kubu pro-kontra memiliki massa pendukung yang semakin besar dari tahun ke tahun.

Pada laman situs organisasi tersebut gayanusantara.or.id terpampang jelas visi dan misi organisasi tersebut. Secara jelas dituliskan bahwa organisasi tersebut merupakan pelopor organisasi gay di Indonesia yang terbuka dan bangga akan jati dirinya serta tidak mempermasalahkan keragaman seks, gender dan seksualitas serta latar belakang lainnya (gayanusantara.or.id). Oleh karena itu, eksistensi LGBT tidak bisa dipandang sebelah mata. Mereka telah menjadi realitas sosial sehingga negara harus aktif dan terlibat. Namun penulis tidak mau terjebak dalam perdebatan tersebut. Bagaimanapun kedua belah pihak memiliki standar kebenaran tersendiri. Penulis lebih tertarik untuk mengkaji dari aspek dinamika dan relasi antara warga negara (LGBT) dengan negara (Pemerintah). Hal ini berangkat dari asumsi dasar bahwa kelainan orientasi seksual mereka tidak menghilangkan status kewarganegaraan beserta hak mereka sebagai warga negara. Oleh 
karena itu, negara masih memiliki kewajiban untuk mereka. Dengan kata lain, LGBT memiliki kedudukan yang sama di depan hukum Indonesia.

Samsu (2018) menyatakan bahwa LGBT harus mendapatkan hak-haknya secara penuh tanpa dikurangi. Di sisi lain, ditemukan dalam Penelitian Gina \& Abby ( 2016) bahwa di Jakarta mayoritas atau $60 \%$ dari responden mengatakan bahwa mereka mendapatkan kekerasan baik dalam bentuk psikologis, fisik, ekonomi, dan seksual. Sehingga mayoritas mereka mengatakan tidak nyaman dengan identitas mereka. Dalam penelitian tersebut juga disebutkan bahwa sebanyak 73,3\% individu LGBT yang melaporkan sebagai korban dikriminasi tidak mendapat respon dari pihak berwenang. Hal tersebut menimbulkan kemirisan kita sebagai manusia.

Dengan menggunakan istilah yang digunakan oleh Gina dan Abby (2016), absennya negara, sikap dan komitemen pemerintah perlu dikritik. Absen dalam hal ini tidak hanya ketiadaan atas respon (penegak hukum) terhadap mereka yang mendapat pelecehan, namun juga ketiadaan kebijakan politik atau hukum yang jelas. Sikap absen atau ambigu oleh pemerintah ini justru menempatkan mereka dalam keadaan lebih mengkhawatirkan. Memang harus diakui bahwa hukum positif Indonesia belum mengatur secara jelas tentang LGBT (Sofyarto, 2018) atau undang-undang anti diskriminasi terhadap gender maupun orientasi seksual (Samsu, 2018). Idealnya ketiadaan hukum ini justru harusnya menjadi ruang kreasi, kontribusi dan manifestasi kehadiran negara dalam menyelesaikan persoalan di masyarakat.

Ketiadaan hukum menunjukkan bahwa negara kurang responsif terhadap keberadaan LGBT. Hal ini sesungguhnya menciderai semangat negara hukum yang tertuang dalam UUD NRI Tahun 1945 Pasal 1 Ayat (3). Lebih ironis ialah sejauh ini belum bisa ditemukan upaya konstruktif dan serius pemerintah terhadap penyelesaian paling tidak dalam upaya memastikan mereka menerima dan menikmati hak-hak mereka sebagai warga negara. LGBT sebagai warga negara juga berhak mendapatkan perlakuan atau keadilan sosial. Diskriminasi dalam bentuk apapun terhadap LGBT tidak bisa dibenarkan baik secara HAM maupun Pancasila (Papilaya \& Ludji, 2016).

Berdasarkan hal tersebut penulis ingin mengkaji tentang eksistensi LGBT dalam perspektif kewarganegaraan Indonesia yang dikaitkan antara HAM, agama, dan Pancasila sebagai sumber dan norma di Indonesia. Hal ini berkaitan dengan hak dan kewajiban mereka yang setali uang dengan apa yang harus negara lakukan terhadap mereka. Dalam hal ini penulis mengkaji kebijakan-kebijakan yang telah ditetapkan oleh Indonesia.

\section{METODE PENELITIAN}

Penelitian ini bersifat kualitatif dan metode yang digunakan adalah studi kepustakaan (library research) yakni dengan mengkaji sumber-sumber yang berkaitan dengan LGBT di Indonesia kaitannya dengan hak asasi manusia, Pancasila, dan agama baik hasil penelitian, kebijakan, dan dokumen yang mendukung. Sumber data primer yang digunakan dalam penelitian ini bersumber dari buku, artikel ilmiah, berita media massa baik online maupun cetak, dan sumber sekunder berasal dari sumber-sumber lain yang mendukung. Data kemudian diolah dan dianalisis secara induktif.

\section{JURNAL KEWARGANEGARAAN}




\section{HASIL DAN PEMBAHASAN}

Kewarganegaraan dan LGBT tidak bisa dipisahkan. Keduanya memiliki keterkaitan dan berdialektika yang sangat erat baik secara konseptual maupun realitas sosial kontemporer. LGBT sebagai salah satu bentuk ekspresi individu, ungkapan perasaan, dan cinta atau dengan kata lain ekspresi hak asasi manusia terlepas bagaimana tafsir negara adalah sesuai yang harus diterima. Dalam pandangan sosiologi kewarganegaraan, gerakan LGBT adalah sesuai yang alamiah dalam masyarakat. Gerakan perempuan dan gerakan gay atau lesbian telah menjadi salah satu gerakan sosial paling menonjol yang menentang model hak kewarganegaraan tradisional dan berusaha untuk membuat model yang lebih inklusif (Nash, 2010). Fenomena LGBT menjadi menarik karena hampir terjadi di seluruh belahan dunia. LGBT juga semakin familiar seiring dikaitkan dengan hak asasi manusia yang semakin masif seiring dengan globalisasi.

Di Indonesia fenomena LGBT menjadi perbincangan di Era Reformasi. Sekalipun beberapa ahli mengatakan bahwa LGBT telah lama ada di Indonesia. Hanya respon publik saat ini yang lebih terbuka seiring dengan keterbukaan informasi dan partisipasi publik. Lesbi misalnya menurut Blackwood (2010) sudah digunakan sejak 1980 yang memiliki kesamaan dengan Lesbian dalam istilah Barat.

Dalam konsep kewarganegaraan, Gerakan LGBT merupakan gerakan melawan ketidaksetaran atau ekslusifitas konsep kewarganegaraan tradisional atau konservatif atau dikenal dengan ketidaksetaraan gender (gender inequalities). Bentuk dari gender inequalities ialah sering kali sebagai individu, mereka tetap tertindas (dibungkam, tidak terlihat atau dikenakan pelecehan di depan umum); sebagai sebuah kelompok, legitimasi politik ,konstituensi mereka dan klaim hak kewarganegaraan mereka dipertanyakan (Isin \& Wood, 1999). Hal ini yang mendorong gerakan agar kewarganegaraan lebih terbuka khususnya terhadap perempuan. Gerakan perempuan diawali pada abad ke-18 di Perancis dan Inggris. Tuntutan atas seksual minoritas adalah gagasan lebih baru. Tuntutan ini mencerminkan keinginan agar hak kewargenegaraan mereka diakui (Lister, 2002).

Pada akhirnya di beberapa negara tuntutan tersebut berhasil. Beberapa negara telah mengeluarkan kebijakan pengakuan terhadap mereka seperti Denmark (1989), United Kingdom (UK) (Equality Act 2010), (The Civil Partnership Act 2004), Netherlands (2001); Belgium (2003; Canada (2005; Spain (2005); South Africa (2006); Sweden (2009); Portugal (2010) to civil unions and registered partnerships (includ-ing France's pacte civil de solidarité in 1999 and New Zealand's Civil Union in 2004) (Taylor, 2011).

Argumentasi penerimaan dan pengakuan LGBT ialah pentingnya kesetaraan hak dalam bentuk inklusi. Dalam pandangan Liberal, gerakan LGTB merupakan suatu bentuk ekspresi perasaan yang harus dihormati. Lesbian, Gay, Transeksual, dan Biseksual merupakan bagian dari membentuk keluarga yang harus dihormati dan dilindungi di mana merupakan hal atau pilihan setiap individu (Taylor, 2011).

Di Indonesia hal ini tentu sangat sulit diterima. Indonesia berbeda dengan negara lain baik dalam budaya maupun ideologi. Indonesia merupakan negara dengan mayoritas penduduk beragama Islam yang sangat keras menentang LGBT (Hefner, 2011). Sehingga kemunculan kalangan LGBT menimbulkan keresehan dan ketakutan sekaligus kebencian. Hal ini menimbulkan aksi-aksi penolakan dari berbagai masyarakat. Demikian juga Pancasila sebagai ideologi sejatinya tidak memperkenankan atau mengakui LGBT. Demikian halnya dalam peraturan perundang-undangan belum ada yang mengatur aau 
mengakui tersebut (Artina, 2016; Samsu, 2018). Sehingga, Kehadiran LGBT juga dianggap sebagai ketakutan (phobia) secara psikis terhadap maskulinitas di Indonesia yang secara mayoritas merupakan heteroseksual (Boellstorff, 2004).

Di sisi lain Indonesia merupakan negara yang aktif dalam memperjuangkan penegakan hak asasi manusia. Khususnya dalam sila kedua Pancasila "Kemanusiaan Yang Adil dan Beradap" mengandung makna bahwa Pancasila memandang kemanusiaan secara holistic yakni mencakup manusia sesuai dengan kodratnya yang mempunyai akal, pikiran, perasaan dan keyakinan (Nurgiansah, 2020).

Sejak kejatuhan Orde Baru, Era Reformasi sangat aktif dan masif dalam mengeluarkan UU berkaitan HAM bahkan aktif meratifikasi kebijakan HAM Internasional. Terlepas apakah hal itu sedikit terpaksa akibat ketatnya pengawasan pemerhati HAM Internasional ke Indonesia atau merupakan kesadaran sendiri (Offord \& Cantrell, 2000). Pancasila sejak awal berdirinya bahkan sebelum DUHAM 1948 sudah mengafirmasikan tentang pentingnya pengakuan HAM (Latif, 2016). Bahkan hasil amandemen UUD memuat bab khusus tentang HAM yakni BAB X Tentang Hak Asasi Manusia. Hal ini menunjukkan bahwa komitmen penegakan di Indonesia sangat tinggi. Era Reformasi mencoba untuk menegakkan moralitas yang sudah lama terkubur dalam stigma Orde Baru dalam pengejaran moralitas dalam ranah politik, sosial, dan agama (Platt et al., 2018).

Ada dilema mendalam secara ideologi maupun paradigma negara Indonesia dalam memandang LGBT. Ada kemungkinan bahwa negara sudah memiliki tafsir dan sikap tersendiri namun mempertimbangkan tekanan atau pandangan dunia luar. Secara nilai, budaya, agama, dan ideologi Pancasila sudah jelas bahwa LGBT sangat bertentangan dan terlarang. Namun hal tersebut masih bersifat norma sosial belum menjadi normal formal (hukum). Norma sosial yang tersebut sangat mungkin disalah tafsirkan karena tidak memiliki institusi dan instruksi yang jelas. Ada kemungkinan yang lain bahwa norma sosial tersebut perlu diubah menjadi normal formal sebagai bentuk penguatan dan pengakuan normal tersebut. Hal ini tergantung kemauan dan kemampuan proses politik legislatif.

Akhirnya pengakuan atau penegasian tentang LGBT yang belum ada hingga saat ini. Sehingga legal atau tidaknya LGBT bersifat multitafsir sebab Indonesia sebagai negara yang dipengaruhi oleh aliran hukum Eropa Kontinental dimana menganut hukum tertulis. Afirmasinya, tidak ada hukum tertulis yang melarang LGBT. Salah satu asas hukum ialah nullum delictum noella poena sine praevia lege poenali yang artinya adalah suatu perbuatan tidak dapat dipidana, kecuali sudah ada hukum yang mengatunya. Afirmasinya, ketiadaan peraturan tertulis yang jelas selain normal sosial tentang LGBT memberikan ruang tafsir yang beragam apakah LGBT terlarang atau tidak.

Fatwa Majelis Ulama Indonesia (MUI) Nomor 57 Tahun 2014 Tentang Lesbian, Gay, Sodomi dan Pencabulan secara jelas dan tegas menyatakan terlarang (haram). Namun posisi fatwa MUI dalam sistem positif Indonesia tidak bersifat mengikat dan hanya suatu bentuk pendapat sekalipun posisinya diakui dalam sistem tata peraturan perundang-undangan Indonesia (Riadi, 2010). Namun sikap pemerintah terhadap fatwa ini juga perlu didengar apakah setuju dan menguatkan atau justru sebaliknya. 
Ketiadaan regulasi yang jelas menjadi ruang untuk masyarakat secara sosial untuk menafsirkan eksistensi LGBT dan parsial. Khususnya kehadiran fatwa MUI menjadi satusatunya sumber legitimasi atas perlakuan mereka terhadap kalangan LGBT. Hal ini kemudian menempatkan para LGBT mudah mendapatkan diskriminasi. Demikian juga jika LGBT korban diskriminasi tersebut melapor ke kepolisian, sulit untuk mendapatkan respon atau perlindungan. Jika pihak kepolisian memproses pengaduan tersebut, maka tuduhan bahwa kepolisian melindungi LGBT sangat mungkin terbentuk di publik demikian juga sebaliknya.

Perlu penegasan bahwa eksistensi mereka tidak bisa dipisahkan, direndahkan atau diubah dalam masyarakat. Mereka tetap memiliki kedudukan yang sama di depan hukum dan Pancasila. Oleh karena itu, diskriminasi terhadap mereka baik dalam hukum, ekonomi, dan sosial adalah sesuatu yang bertentangan dengan HAM dan Pancasila itu sendiri (Sujana et al., 2018). Di sisi lain harus ditegaskan bahwa bukan berarti negara bebas untuk menghukum atau mengkriminalisasi LGBT sebab sulitnya batasan moral yang menjadi pembahasan dalam mengungkap persoalan tersebut (Artina, 2016). Afirmasinya ialah negara harus hadir sebagai solusi dan penengah diantara pertentangan dan perdebatan publik. Negara pasif dan hanya mengikuti opini publik. Ketiadaan produk hukum yang jelas dan eksplisit yang menunjukkan sikap pemerintah terhadap LGBT adalah bentuk diskriminasi tersendiri.

Dalam hal ini diperlukan terobosan dan ketegasan negara dalam kaitan politik hukum Indonesia. Sekalipun LGBT terlarang secara budaya dan norma Indonesia, bukan berarti mereka mudah dipersekusi. LGBT dengan stigma yang ada pada diri mereka tetap memiliki hak dan kedudukan setara di hadapan hukum. Dengan kata lain, mereka harus tetap dilindungi oleh hukum. Konsekuensinya, setiap orang yang melakukan pelecegan, pelanggaran, atau diskriminasi harus diproses secara hukum. Namun, perlu ditegaskan bahwa yang dilindungi adalah individu LGBT sebagai warga negara bukan aktivitas seksual mereka sebab belum ada legalisasi secara hukum. LGBT wajib dilindungi dari diskriminasi, bullying, kekerasan, dan segala bentuk pelanggaran HAM lainnya (Yansyah \& Rahayu, 2018). Hal ini penting ditegaskan agar tidak multitasfsir.

Permasalahan krusial lain adalah sikap diskriminasi yang dialami oleh kalangan LGBT. Diskriminasi dalam hal ini ialah baik dari masyarakat secara sosial maupun dari aparat negara berdasarkan hasil penelitian Gina, \& Abby (2016). Di satu sisi pemerintah boleh mengatakan bahwa perkara legitimasi LGBT secara budaya atau sudah jelas yakni tidak menerima (Kominfo, 2020). Namun di sisi lain, kalangan LGBT mendapatkan represi dan persekusi di masyarakat bahkan aduan mereka kurang mendapatkan respon dari aparat penegak hukum.

Kehadiran negara diperlukan agar memberikan pegangan sekaligus pandangan terhadap LGBT agar masyarakat memiliki keteguhan dalam bersikap. Fakta bahwa ada pergeseran persepsi dan penerimaan masyarakat LGBT adalah sesuatu yang mengkhawatirkan. Jika masyarakat semakin terbuka dengan LGBT maka akan mudah menimbulkan pergesekan dan konflik di masyarakat yang sejauh ini kukuh menolak LGBT. Saat ini kalangan muda yang mulai menerima LGBT semakin bertambah (Saroh \& Relawati, 2017). Sekali lagi, kita kesulitan menafsirkan hal tersebut apakah penerimaan itu benar atau tidak. 


\section{SIMPULAN}

Indonesia mengalami dilema filosofis maupun ideologis terhadap LGBT. Di satu sisi, Indonesia dengan negara mayoritas muslim dan beberapa agama lain sangat menentang perilaku LGBT. Di sisi lain, Indonesia bukanlah negara agama. Hal ini bisa dilihat lahirnya Fatwa MUI Tentang LGBT yang secara tegas menolak, namun tidak memiliki kekuatan hukum kepada masyarat maupun negara. Hanya bersifat pendapat. Di sisi lain, semangat penegakan HAM di Indonesia Era Reformasi harus konsisten di mata dunia internasional. Logika kuat atas eksistensi LGBT tidak lain adalah tafsir atas hak asasi manusia. Realitas sosial yang mengkhawatirkan adalah kalangan LGBT mendapatkan perlakuan diskrimatif baik secara politik, ekonomi, dan sosial. Paradoks dengan hal tersebut ialah penerimaan kalangan muda atas eksistensi LGBT semakin meningkat dan masif. Ketiadaan sumber, konsep, dan regulasi terhadap LGBT di Indonesia tidak bisa dibiarkan. Hal ini akan menimbulkan keambiguan di masyarakat. Ketiadaan sumber hukum dan kebijakan yang jelas terhadap LGBT adalah bentuk diskriminasi oleh negara. LGBT harus diperlakukan sama dan setara dengan masyarakat lainnya. Kelainan orientasi seksual tidak menghapuskan hak dan kewajiban mereka terhadap dan atas negara. Afirmasinya, negara harus segera memberikan sikap yang tegas atas realitas LGBT di Indonesia.

\section{UCAPAN TERIMA KASIH}

Terima kasih kepada penulis yang tergabung dalam kepenulisan ini. Semoga ini bermanfaat dan memberikan kontribusi positif. Masih banyak kekurangan dalam artikel ini baik kualitas isi maupun sumber data sehingga memerlukan masukan dan penelitian mendalam.

\section{DAFTAR PUSTAKA}

Artina, D. (2016). Kedudukan LGBT dalam Hukum Negara Republik Indonesia ditinjau dari perspektif Pancasila. Seminar Nasional Hukum Universitas Negeri Semarang, 2(1), 195-206.

Blackwood, E. (2010). Falling Into the Lesbi World: desIre and Difference in Indonesia. In Falling into the Lesbi World: Desire and Difference in Indonesia.

Boellstorff, T. (2004). The Emergence of Political Homophobia in INDONESIA: Masculinity and National Belonging. Ethnos, 69(4), 465-486. https://doi.org/10.1080/0014184042000302308

Gina, G. A. \& A. (2016). Queering Indonesia: When the State is Absent :A Study of LGBT Community in Jakarta. Indonesian Feminist Journal, 4(1), 4-14.

Hefner, R. W. (2011). Civil Islam: Muslims and democratization in Indonesia. In Civil Islam: Muslims and Democratization in Indonesia. https://doi.org/10.2307/3557788

Isin, E. F., \& Wood, P. K. (1999). Citizenship and Identity. Sage Publications.

\section{JURNAL KEWARGANEGARAAN}


Kominfo. (2020). No Title. https://kominfo.go.id/content/detail/6856/pemerintahkonsisten-jalankan-kostitusi-tidak-melayani-pernikahan-sejenis/0/rilis_media_gpr

Lister, R. (2002). Sexual Citizenship. In E. F. Isin \& B. S. Turner (Eds.), Handbook of Citizenship Studies. Sage Publications.

Nash, K. (2010). Contemporary Political Sociology: Globalization, Politics, and Power (Second Edition). Wiley-Blackwell.

Nurgiansah, T. H. (2020). Fenomena Prostitusi Online di Kota Yogyakarta dalam Perspektif Nilai Kemanusiaan Yang Adil dan Beradab. Jurnal Kewarganegaraan, 17(1), 27. https://doi.org/10.24114/jk.v17i1.14208

Offord, B., \& Cantrell, L. (2000). Homosexual Rights as Human Rights in Indonesia and Australia. Journal of Homosexuality, 40(3-4), 233-252. https://doi.org/10.1300/J082v40n03_12

Papilaya, J. O., \& Ludji, I. (2016). Lesbian, Gay , Biseksual, Transgender (LGBT) dan Keadilan Sosial. PAx Humara, 3, 25-34.

Platt, M., Davies, S. G., \& Bennett, L. R. (2018). Contestations of Gender, Sexuality and Morality in Contemporary Indonesia. Asian Studies Review, 42(1), 1-15. https://doi.org/10.1080/10357823.2017.1409698

Riadi, M. E. (2010). Kedudukan Fatwa Ditinjau dari Hukum Islam dan Hukum Positif. Ulumuddin, VI, 468-477.

Samsu, H. (2018). Kedudukan Lesbian, Gay, Biseksual, dan Transgender (LGBT) di Indonesia Ditinjau dari Perspektif Hak Asasi Manusia. Lex Et Societatis, VI(6), 1320. https://doi.org/10.1017/CBO9781107415324.004

Santoso, M. B. (2016). LGBT dalam Perspektif Hak Asasi Manusia. Share : Social Work Journal, 6(2), 220. https://doi.org/10.24198/share.v6i2.13206

Saroh, Y., \& Relawati, M. (2017). Indonesian Youth'S Perespective Towards Lgbt. Humanus, 16(1), 71. https://doi.org/10.24036/jh.v16i1.7323

Sofyarto, K. (2018). Abu-abu Regulasi LGBT di Indonesia. Selisik, 4(6), 84-94.

Sujana, I. N., Setyawati, K. A., \& Ujanti, N. M. P. (2018). The Existence of the Lesbian, Gay, Bisexual and Transgender (Lgbt) Community in the Perspective of a State Based on Pancasila. Mimbar Hukum - Fakultas Hukum Universitas Gadjah Mada, 30(1), 126. https://doi.org/10.22146/jmh.28655

Taylor, Y. (2011). Lesbian and Gay Parent's Sexual Citizenship: Recognition, Belonging and (Re)classification. In Janice McLaughlin, P. Phillimore, \& Diane Richardson (Eds.), Contesting Recognition: Culture, Identity and Citizenship. Palgrave Macmillan. https://doi.org/10.1017/CBO9781107415324.004

UNDP. (2014). Being LGBT in Asia: Indonesia Country Report.

Wibowo, A. (2015). Tinjauan Teoritis Terhadap Wacana Kriminalisasi LGBT. Cakrawala Hukum, X, 120-151.

Yansyah, R., \& Rahayu, R. (2018). Globalisasi Lesbian, Gay, Biseksual, Dan Transgender (Lgbt): Perspektif HAM dan Agama dalam Lingkup Hukum di Indonesia. Law Reform, 14(1), 132. https://doi.org/10.14710//r.v14i1.20242. 